\title{
A patient presenting with features of progressive multifocal leucoencephalopathy in HIV/AIDS
}

\author{
A A P T Chang', S Jayasinghe ${ }^{2}$, S Rajapakse ${ }^{3}$ and M H R Sheriff ${ }^{4}$ \\ (Index words: Papova JC virus, EEG, contrast CT scan)
}

\section{Introduction}

Progressive multifocal leucoencephalopathy (PML) is associated with infection of oligodendrocytes by the papovavirus JC (the initials of the patient whose tissue was used to isolate the virus; not Jakob-Creutzfeldt disease). This leads to demyelination of the white matter. It is characterised by dementia, dysphasia, pyramidal tract involvement and persistently normal CSF analysis. The course is inexorably progressive with many dying within six to nine months of diagnosis. PML prevalence rates of 3 to $5 \%$ have been reported in patients with AIDS (1). However, PML as the AIDS defining diagnosis is extremely rare in Asia (2). We report here a patient who presented with neurological manifestations of PML, which is a rare but recognised AIDS indicator condition.

\section{Case report}

A previously healthy, 49-year old woman was admitted with a low grade intermittent fever of three weeks' duration, a single generalised tonic clonic seizure, followed by progressive weakness of the left upper and lower limbs. She was emaciated and had generalised discrete lymphadenopathy, and oral thrush. White exudates were seen in the left fundus. Her minimental score, which was 24 on admission, rapidly deteriorated to a state of confusion.

Contrast CT scan of the brain showed non-enhancing hypodense lesions confined to the white matter of the right parietal and left frontal territories with no mass effect (Figure). The EEG was grossly abnormal with bursts of slow delta discharges over the fronto-temporal regions (left $>$ right). CSF analysis showed a protein-cytological dissociation (proteins $120 \mathrm{mg} / \mathrm{dl}$; 6 lymphocytes; glucose 80 $\mathrm{mg} / \mathrm{dl})$. Serology for CMV, EBV, and toxoplasma antibodies were negative. ESR was persistently more than $135 \mathrm{~mm}$. Both ELISA and Western blot for HIV antibodies were positive. The CD4 cell count was $160 /$ microlitre. The patient died 3 weeks after admission.

PML was considered the most probable diagnosis in this patient. Diagnostic criteria included rapid onset $(<2$ weeks) of multifocal neurological symptoms and signs, advanced immunosuppression and asymmetric uni- or multifocal white matter lesions without mass effect, contrast enhancement or cortical atrophy on neuro-imaging (3).

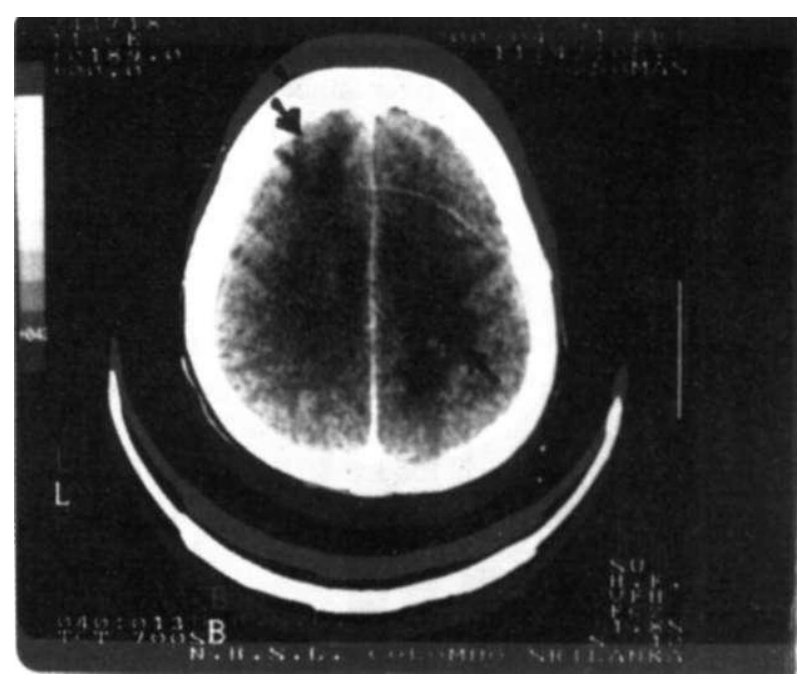

Figure. Contrast CT scan of brain showing non-enhancing hypodense lesions (arrows) confined to the white matter of the right parietal and left frontal lobes with no mass effect.

\section{Discussion}

This patient had evidence of PML with underlying AIDS. She had clinical, radiological and laboratory features suggestive of PML, using established criteria (3). This is a rare diagnosis and cerebral toxoplasmosis, primary cerebral lymphoma and HIV encephalopathy can mimic the clinical features. There was no serological evidence to support the diagnosis of toxoplasmosis. In PML, CT or MRI scan of the brain shows hypodense lesions in the cerebral white matter. The lack of mass effect or contrast enhancement usually helps to distinguish PML from toxoplasmosis and primary cerebral lymphoma in HIV infected patients presenting with focal neurological signs. The multiple foci and the asymmetric appearance differentiate PML from symmetric diffuse white matter change characteristic of HIV encephalopathy.

Other sophisticated tests to diagnose PML include, T2 weighted cranial MRI and polymerase chain reaction (PCR) for detection of papova JC viral DNA in the CSF (4). The latter has been found to have a sensitivity of about $75 \%$ and a specificity of between $90 \%$ and $99 \%$ (5). In centres where there are no facilities to do such tests, brain biopsy remains the only way to make a definitive diagnosis.

'•'Lecturers, Associate Professor and 'Professor, Department of Clinical Medicine, Faculty of Medicine, University of Colombo. (Revised version accepted 27 October 2001. Corresponding author AAPTC) 
since CSF, serology and EEG are non-specific. However, in the appropriate clinical setting, asymmetric white matter lesions without mass effect or enhancement on CT or MRI scan of the brain are characteristic of PML (6). We had no facilities for MRI in this patient and a brain biopsy was not done, but there was adequate evidence to suggest, on the basis of "high probability', a diagnosis of PML.

PML occurs in immunocompromised states such as lymphoproliferative and myeloproliferative disorders, granulomatous disease and chronic inflammatory disorders. Its prevalence has risen since the advent of the AIDS pandemic. The seemingly higher incidence of PML in AIDS than in any other disorder of immunosuppression raises the possibility of an interaction between the $\mathrm{JC}$ and HIV viruses (7). The peak age incidence was in the sixth decade but with the spread of HIV, it has shifted to younger ages, with a male preponderance. Yet it is rare for PML to present as the AIDS-defming diagnosis (1). In one of the largest descriptions in Asia that included $2261 \mathrm{HIV}$-seropositive patients of which $15 \mathrm{~S} 3(68.7 \%)$ had AIDS, not a single case of PML was reported as the AIDS-defining diagnosis (2).

\section{References}

1. Berger J. PML in AIDS. Neurology 1992; 42: 1845.

2. Tansuphasawadikul S, Amornkul PN, Tanchanpong C, Limpakarnjanarat K, Kaewkungwal J, et al. Clinical presentation of hospitalized adult patients with HIV infection and AIDS in Bangkok, Thailand. Journal of Acquired Immune Deficiency Syndromes 1999; 21: 326-32.

3. Von Giesen HJ, Neun Jacob E, Dorries K, Jablonowski H, Roick $\mathrm{H}$, Arendt G. Diagnostic criteria and clinical procedures in H1V1 associated progressive multifocal leucoencephalopathy. Journal of Neurological Science 1997; 147: 63-72.

4. Berger JR, Major EO. Progressive multifocal leucoencephalopathy. Seminars in Neurology 1999; 19: 193-200.

5. Cinque P, Vago L, Dahl H. Polymerase chain reaction on cerebrospinal fluid for diagnosis of virus associated opportunistic diseases of the central nervous system. AIDS 1996; 19:951-8.

6. Brain J Seeney. Rob F Miller, Michael JG Harrison. Review: progressive multifocal leucoencephalopathy. British Journal of Hospital Medicine 1993; 50: 187-92.

7. Manji H, Miller RF, eds. Progressive multifocal leucoencephalopathy: progress in the AIDS era. Journal of Neurology, Neurosurgery and Psychiatry 2000; 69: 569-71. 